\title{
The Probable Source of Certain Spurious Frequencies Found in the Output of a Variable Speed Generating System Using Slip Recovery
}

P. Carlin

June 1989

Prepared for the 24th

Intersociety Energy Conversion

Engineering Conference

Washington, D.C.

6-11 August 1989

Prepared under Task No. WE933101

Solar Energy Research Institute

A Division of Midwest Research Institute

1617 Cole Boulevard

Golden, Colorado 80401-3393

Prepared for the

U.S. Department of Energy

Contract No. DE-AC02-83CH10093 


\section{NOTICE}

This report was prepared as an account of work sponsored by an agency of the United States government. Neither the United States government nor any agency thereof, nor any of their employees, makes any warranty, express or implied, or assumes any legal liability or responsibility for the accuracy, completeness, or usefulness of any information, apparatus, product, or process disclosed, or represents that its use would not infringe privately owned rights. Reference herein to any specific commercial product, process, or service by trade name, trademark, manufacturer, or otherwise does not necessarily constitute or imply its endorsement, recommendation, or favoring by the United States government or any agency thereof. The views and opinions of authors expressed herein do not necessarily state or reflect those of the United States government or any agency thereof.

\section{Printed in the United States of America}

Available from:

National Technical Information Service

U.S. Department of Commerce

5285 Port Royal Road

Springfield, VA 22161

Price: Microfiche A01

Printed Copy A02

Codes are used for pricing all publications. The code is determined by the number of pages in the publication. Information pertaining to the pricing codes can be found in the current issue of the following publications which are generally available in most libraries: Energy Research Abstracts (ERA); Government Reports Announcements and Index (GRA and I); Scientific and Technical Abstract Reports (STAR); and publication NTIS-PR-360 available from NTIS at the above address. 


\title{
THE PROBABLE SOURCE OF CERTAIN SPURIOUS FREQUENCIES FOUND IN THE OUTPUT OF A VARIABLE SPEED GENERATING SYSTEM USING SLIP RECOVERY
}

\author{
Palmer W. Carlin \\ Solar Energy Research Institute \\ Golden, CO
}

\begin{abstract}
As part of U.S. Department of Energy-sponsored research on wind energy, a Mod-0 wind turbine was used to drive a variable-speed, wound-rotor, induction generator. Energy resulting from the slip frequency voltage in the generator rotor was rectified to DC, inverted back to utility frequency $\mathrm{AC}$, and injected into the power line. Spurious changing frequencies displayed in the generator output by a spectrum analyzer are caused by ripple on the DC link. No resonances of any of these moving frequencies were seen in spite of the presence of a bank of power factor correcting capacitors.
\end{abstract}

\section{INTRODUCTION}

For many years, the first of a series of NASAdesigned wind machines was operated at the NASA-Lewis Plum Brook Station near Sandusky, Ohio. This Mod-0 machine was used for a variety of aerodynamic, performance, electrical, and loads tests. Although many transmission gear ratios were used, the conventional synchronous and induction generators used meant that energy was collected at essentially constant rotor speed. The last series of tests run just before the machine was dismantled in 1987 was introduced to investigate variable speed generating systems.

One of those tests used a conventional slip recovery system. Figure 1 is a one-line diagram of this generator and its associated power electronics system. Note that the stator is excited directly with line voltage at the utility frequency. The generator's wound rotor is connected to the input side of the DC current link through a simple three-phase bridge, and the output of the link is attached to the utility line through a commercial line-commutated inverter. The rotor, when either above or below synchronous speed, supplies a variable voltage at a variable frequency proportional to slip. In either case, variable frequency power from the rotor becomes DC, is inverted to $60 \mathrm{~Hz}$, and is injected into the line as recovered power.

The technology of power electronics allows amazing control of large electric machines. Unfortunately, however, the fact that we slice individual cycles of current creates important harmonic frequency components in that current. The data collected during the Mod- 0 tests have yielded some interesting spectrograms of generator current showing the expected odd harmonics of a linecommutated inverter. Also present, however, are other components of changing frequency. This paper discusses the relation of some of these harmonics to the changing rotor speed.

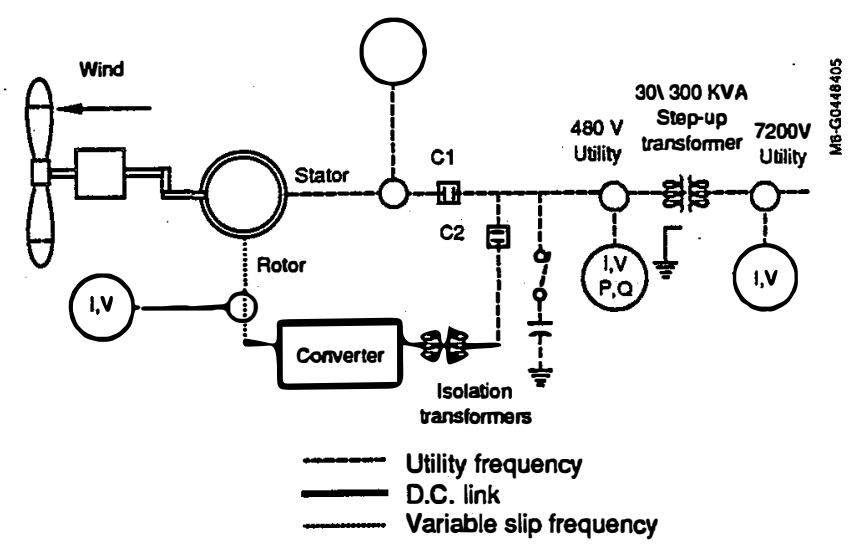

Figure 1. One-line diagram of the slip recovery system.

\section{EXPERIMENTAL SETUP AND MEASUREMENTS}

The data supporting this report were obtained from voltages and currents that were measured on each of the three generator phases through $1000 \mathrm{~Hz}$ bandwidth channels and recorded on a Honeywell 5600E analog tape recorder. Note that both the secondary or $480 \mathrm{~V}$ side and the primary or $7200 \mathrm{~V}$ side of the utility transformer were instrumented. Subsequently, these records were analyzed off line with a Scientific-Atlanta Model SD380Z spectrum analyzer to obtain the spectrograms presented here.

\section{RESULTS}

The current supplied to the utility was measured on the $7200 \mathrm{~V}$ side of the utility transformer. A twodimensional or waterfall diagram of the spectrum of one phase of this current is shown in Figure 2. The transverse dimension displays frequency from zero to about $600 \mathrm{~Hz}$. The longitudinal dimension displays time and shows how the spectrum changes at 1 -second intervals. The vertical scale is the linear (not logarithmic) amplitude of the current spectral components. The amplitude of the $(60 \mathrm{~Hz})$ fundamental has been truncated to about $20 \%$ of its actual value for plotting.

If the skew, which gives the three-dimensional effect in Figure 2, is removed, and more data are appended on the time axis, we have the waterfall diagram of Figure 3. 


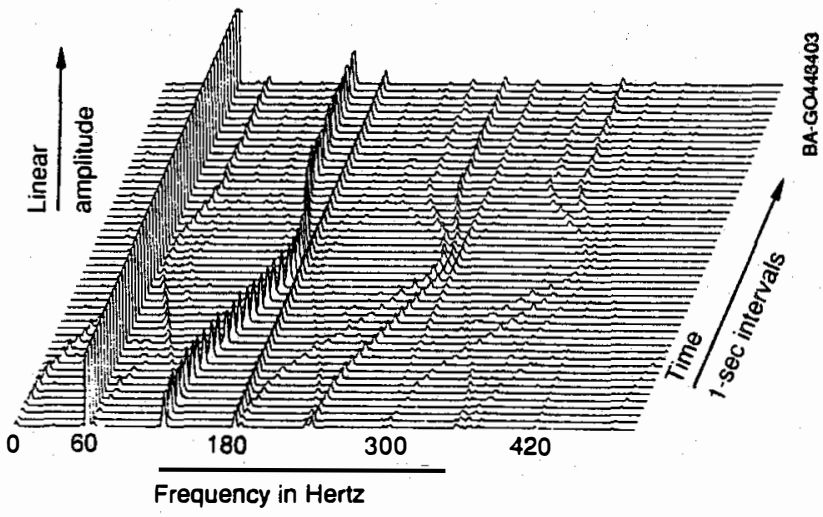

Figure 2. Time history of the spectrum of the primary current.

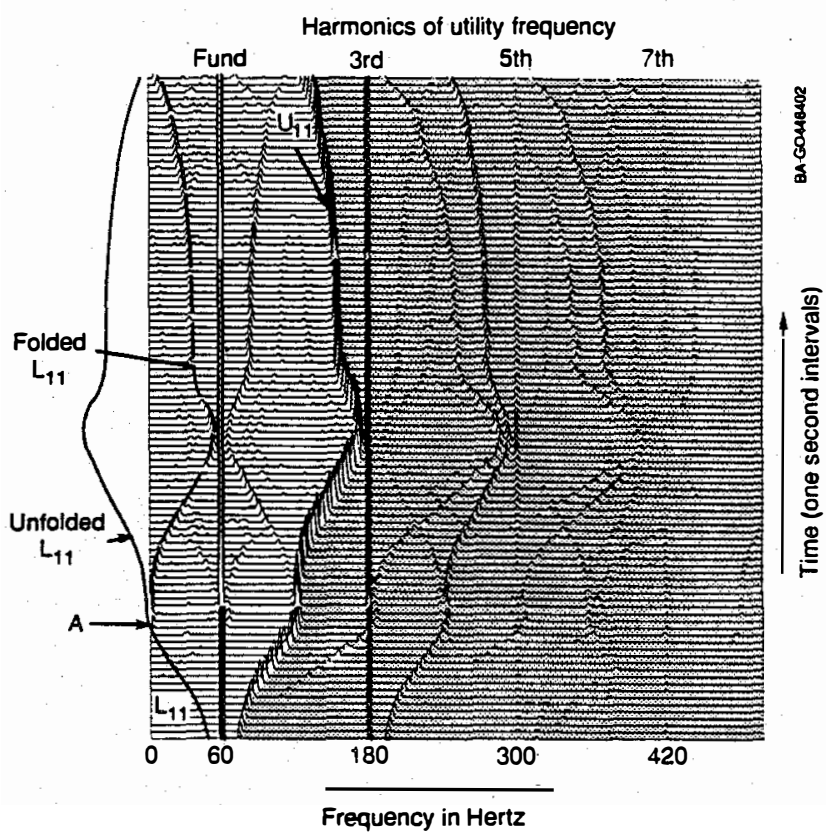

Figure 3. Spectrum with skew removed and showing the unfolded lower sideband.

Suppressing the skew allows the symmetries of the spectrum to be more easily deduced.

It is easy to identify the third harmonic of the $60 \mathrm{~Hz}$ waveform, as well as the fif th and seventh harmonics at $300 \mathrm{~Hz}$ and $420 \mathrm{~Hz}$, respectively. They are the vertical lines of Figure 3, denoting that the frequency is invariant with respect to time, the vertical axis.

Since the DC-to-AC conversion was done with a 12 pulse inverter circuit, harmonics lower than the eleventh should theoretically be missing. Therefore, the phase currents were very carefully examined, and it was found that they were sufficiently dissimilar to account for the harmonics observed. The third harmonic consisted mostly of positive sequence component, and the ninth consisted mostly of negative sequence component. Fifth and sev- enth were negative and positive, respectively, as would be expected. The probable source of this dissimilarity was the presence of some single-phase loads.

\section{DISCUSSION}

The most startling feature in Figure 3 is the presence of moving frequency components. In an ideal ACDC-AC link with perfectly.constant DC, there is no way for frequency information to be transferred from one $A C$ system to the other. The two AC systems on either side of the DC link should have completely unrelated frequencies and reactive power flows.

Because this plainly is not the case, let us calculate the iipple to be expected on the $D C$ bus in the region about two-thirds of the way up the diagram. Because the three-phase bridge rectifier connecting the variable generator rotor $A C$ to the $D C$ bus was a conventional sixpulse type, we will see six pulses for every period of input voltage. In addition, the generator (a four-pole type) produced two electrical cycles for every mechanical slip cycle. From a recorder trace not shown here, we know the generator speed at this time was $2270 \mathrm{rpm}$. The ripple frequency on the DC link for this four-pole generator is therefore:

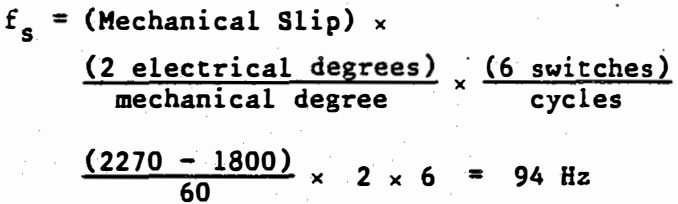

Although it is true that there is a frequency component present at about $94 \mathrm{~Hz}$ in Figure 3 for this time slot, it is moving in the wrong direction for it to be the ripple frequency. That is, as the generator accelerates, this frequency goes down and vice versa. However, if we calculate the ripple as above for several other generator speeds, we soon see that the ripple frequency is always equal to the difference in frequency between the strongest "wandering" component, $U_{11}$, and the $60 \mathrm{~Hz}$ fundamental. This, of course, suggests an amplitude modulation phenomenon, with the strange component being an upper sideband on the $60 \mathrm{~Hz}$ fundamental thought of as a carrier frequency, and the ripple on the DC acting as modulating frequency.

We immediately look for the complementary lower sidebands and find a weak one, $L_{11}$, near the bottom of the spectrogram where the generator speed was not far above synchronous and, therefore, the rotor voltage was fairly low. However, the ripple or modulating frequency soon exceeds the $(60 \mathrm{~Hz})$ carrier at " $A$," which implies a "negative" frequency for the lower sideband. If we take the frequency component that appears to continue from where this lower sideband went negative and "unfold" it around zero into the negative region, we observe the symmetry with the upper sideband. In the entire region, the frequency difference between either sideband and the fundamental carrier is now always the calculated ripple frequency.

The ripple waveform on the current of the DC link is formed from six sinusoidal positive peaks of the three- 
phase bridge and, therefore, has not only odd but also even frequency components. It is not surprising, then, to find upper and lower sidebands, $U_{12}$ and $L_{12}$, with frequency differences of twice the ripple frequency (i.e., a second harmonic). In Figure 4 we see again the lower sideband, which must be unfolded to display its symmetry with respect to its upper sideband. Also, when the frequency changes, we note as a corroborating fact that these second harmonic sidebands change at twice the rate of the first harmonic sidebands described above. Note their comparative slopes in Figure 3.

Because the modulating frequency contains all harmonics of the ripple frequency, it is not surprising to find traces of a third harmonic, $\mathrm{U}_{13}$ and $\mathrm{L}_{13}$. Notice in Figure 3 that these third harmonics change three times as fast as the fundamental.

The reader has probably noticed that even if all the previously mentioned components are removed from the given spectrum, a number of frequencies remain. If we now assume that the constant frequency third, fifth, and seventh harmonics can act as carriers, we can lift off successive families of sidebands centered on these frequencies until the entire spectrogram is explained. For example, the two pairs of sidebands on the third harmonic of the utility frequency, $U_{31} L_{31}$ and $U_{32} L_{32}$, which result from the second and third harmonics of the DC link ripple frequency, are shown in Figure 5.

It is easy, albeit tedious, to find segments of the same pairs of sidebands enclosing the utility fifth and seventh harmonics.

In summary, the output of a current link inverter by its nature provides the desired fundamental $60 \mathrm{~Hz}$ component together with moderate levels of odd harmonics at least up through the thirteenth. At the same time, the input three-phase bridge provides the desired DC com-

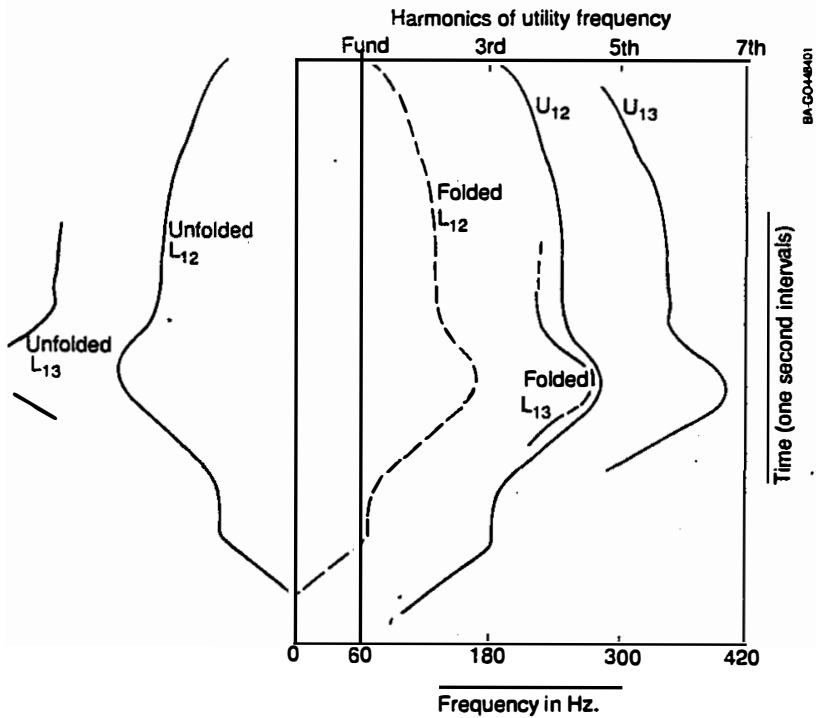

Figure 4. Upper and lower sidebands of the second and third harmonics of the ripple frequency.

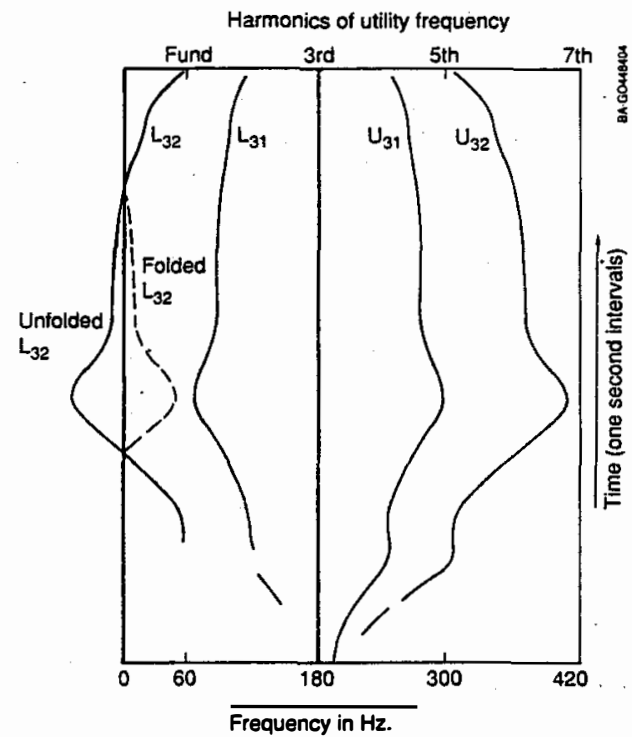

Figure 5. Upper and lower sidebands on the utility third harmonic carrier caused by ripple frequency and its second harmonic.

ponent of the input to the inverter as well as measurable levels of the fundamental, second, and third harmonics of the "wild," or variable AC. The resulting mixing of these two sets of frequencies in the nonlinear characteristic of the inverter gives birth to all the preceding sidebands. Although we have not verified it quantitatively, the amplitudes of these sidebands show the expected variation. Because the amplitude of the AC voltage from the generator rotor is proportional to slip frequency, and because the sideband amplitudes are proportional to the product of the amplitudes of the two frequencies that combine to create them, it appears that the largest wandering frequency grows and wanes in proportion to the magnitude of slip frequency.

Finally, one reason for concern about power system harmonics is that when power factor correction capacitors are present, there is the possibility of resonance and the consequent overvoltage. This is especially true if continuously varying components are present such as those shown here. During these experiments, the Mod-0 did, in fact, have $100 \mathrm{kVAR}$ of capacitance connected near the output of the inverter as shown in Figure 1.

Let us assume that a resonance could be recognized in our diagram by a noticeable increase in amplitude when any variable frequency approached that resonant frequency. The only possible candidate in this spectrum is the prominent first upper sideband of $60 \mathrm{~Hz}, U$ which grows as its frequency increases from about 70 to just under $180 \mathrm{~Hz}$. This nearly 3 to 1 frequency ratio is too wide to be a resonance. In addition none of the other harmonics just below $180 \mathrm{~Hz}$ shows any marked change in amplitude with frequency. From this we concluded that resonances were not present in this particular experiment. 


\section{RECOMMENDATIONS}

Although the preceding results seem to provide evidence opposing the selection of the slip recovery principle in a variable speed generating system, one should not immediately leap to that conclusion. Recall that the amplitudes of all these wandering components are proportional to the products of the amplitude of the utility frequencies and the residual ripple on the DC link. Two obvious improvements might be introduced.

The complete elimination of the ripple on the link is the ideal solution because all the wandering amplitudes would go to zero. Realistically, a combination of additional filtering of the DC link and a 12-pulse rectifier for the DC could be introduced. Not only are the ripple harmonics double frequency, but their relative amplitudes are less.
The other factor in the amplitude product is what we have been calling the carrier. Better balancing of the phases of the generating system would ameliorate all harmonics below the eleventh; however, real life loads are nearly always unbalanced.

The slip recovery system described here plainly has the disadvantage that any resonance in the sweep range of the harmonics generated will certainly be excited from time to time. Other variable speed schemes involving alternative components such as pulse width and highfrequency resonant mode inverters are being tested. Nevertheless, the slip recovery system remains the simplest and cheapest for "off-the-shelf" design, and it needs to handle only a fraction of the total generated power. 